\title{
Neutron Production in Thick Targets Irradiated with High-Energy Ions
}

\author{
S. R. Hashemi-Nezhad, ${ }^{1}$ M. Zamani-Valasiadou, ${ }^{2}$ M. I. Krivopustov, ${ }^{3}$ R. Brandt, ${ }^{4}$ \\ W. Ensinger, ${ }^{5}$ R. Odoj, ${ }^{6}$ and W. Westmeier ${ }^{4,7}$
}

${ }^{1}$ Institute of Nuclear Science, School of Physics, University of Sydney, Sydney, NSW 2006, Australia

${ }^{2}$ Physics Department, Aristotle University, 54124 Thessaloniki, Greece

${ }^{3}$ Joint Institute for Nuclear Research, 141980 Dubna, Russia

${ }^{4}$ Fachbereich Chemie, Philipps Universität, 35032 Marburg, Germany

${ }^{5}$ Institut für Materialwissenschaften, Technische Universität Darmstadt, 64287 Darmstadt, Germany

${ }^{6}$ Forschungszentrum Jülich GmbH, 52425 Jülich, Germany

${ }^{7}$ Dr. Westmeier GmbH, 35085 Ebsdorfergrund, Germany

Correspondence should be addressed to R. Brandt, brandtr@staff.uni-marburg.de

Received 18 April 2011; Accepted 12 July 2011

Academic Editor: Ali Hussain Reshak

Copyright (๑) 2011 S. R. Hashemi-Nezhad et al. This is an open access article distributed under the Creative Commons Attribution License, which permits unrestricted use, distribution, and reproduction in any medium, provided the original work is properly cited.

The neutron production in thick targets irradiated with $1 \mathrm{GeV}$ protons was studied experimentally, and results are well understood with model calculations, including MCNPX 2.7a. However, one observes very large neutron production rates in the interaction of $44 \mathrm{GeV}^{12} \mathrm{C}$ onto thick $\mathrm{Cu}-, \mathrm{Pb}$-, and $\mathrm{U}$-targets beyond calculated rates. The experimental spallation product yield curve in a $20 \mathrm{~cm}$ thick $\mathrm{Cu}$ target irradiated with $72 \mathrm{GeV}^{40} \mathrm{Ar}$ also cannot be reproduced by several model codes, including MCNPX 2.7a. This may be due to secondary fragments produced in high energy $\left(E_{\text {kinetic }}>10 \mathrm{GeV}\right)$ heavy-ion interactions which destroy target nuclei more effectively than primary ions. These observed experimental facts constitute "unresolved problems" from a fundamental point of view. It may have an impact on radiation protection issues for future heavy-ion accelerators.

\section{Introduction}

Recent investigations on the interaction of relativistic ions (called primaries in this paper) above a total energy $E_{\text {kin }}>$ $10 \mathrm{GeV}$ in thick heavy-element targets show unexpected phenomena in the spallation yield distributions, as well as surprisingly intense neutron emission. These unexpected phenomena constitute "unresolved problems" as described in [1, 2].

(1) Spallation mass-yield curves in any thin target are completely understood with conventional reaction models like "limiting fragmentation" and "factorisation" $[1,2]$. However, the spallation mass-yield curves in thick targets which are also produced by secondary fragments, generated in the interaction of primaries with target nuclei, are incompatible with these concepts of "limiting fragmentation" and "factorisation." Secondary fragments, in the following called secondaries, seem to release more neutrons when they interact than primaries.

(2) The neutron emission from thick targets irradiated with ions having $E_{\text {kin }}>10 \mathrm{GeV}$ is rather intense, in particular for $44 \mathrm{GeV}^{12} \mathrm{C}$ and $72 \mathrm{GeV}^{40}$ Ar onto thick $\mathrm{Cu}$ - and $\mathrm{Pb}$-targets. These phenomena need further investigation.

Experimental results published for thick targets irradiated with relativistic ions are scarce and sometimes contradictory. In the experiment on "neutron yields from $1 \mathrm{GeV}$ / nucleon ${ }^{238} \mathrm{U}$ ion beams on Fe target" by Yordanov et al. [3], the neutron spectra above $50 \mathrm{MeV}$ were studied. The authors could fit their experimental data with well-known models and stated (quote) that "after a first beam-target collision the projectile residue may subsequently undergo the same type 
TABLE 1: The direct measurement of neutron production in THICK Pb-targets irradiated at the Synchrophasotron [11].

(a) The total number of neutrons $n$, generated by one primary ion $\left({ }^{1} \mathrm{H},{ }^{2} \mathrm{H},{ }^{4} \mathrm{He}\right.$, or $\left.{ }^{12} \mathrm{C}\right)$ in a very thick lead target $(\Phi=20 \mathrm{~cm}$ and $L=60 \mathrm{~cm})$ and moderated within $1 \mathrm{~m}^{3}$ paraffin, was measured by Vasil'kov et al. This work started in Dubna around 1980. The last column gives the ratio of the neutron yields at the energy $E_{\text {kin }} / A=3.7 \mathrm{GeV}$ compared with the $E_{\text {kin }} / A=1.0 \mathrm{GeV}$.

\begin{tabular}{lcccc}
\hline Ion & Mass $A$ & $\begin{array}{c}\text { Number of neutrons } n \text { at } \\
1 \mathrm{GeV} \text { per nucleon }\end{array}$ & $\begin{array}{c}\text { Number of neutrons } n \text { at } \\
3.7 \mathrm{GeV} \text { per nucleon }\end{array}$ & $\begin{array}{l}n \text { at }\left(E_{\mathrm{kin}} / A=3.7 \mathrm{GeV}\right) \\
n \text { at }\left(E_{\mathrm{kin}} / A=1.0 \mathrm{GeV}\right)\end{array}$ \\
\hline $\mathrm{H}$ & 1 & $21.3 \pm 0.6$ & $68.1 \pm 2.5$ & $3.2 \pm 0.2$ \\
$\mathrm{H}$ & 2 & $45.8 \pm 1.2$ & $157 \pm 3$ & $3.4 \pm 0.2$ \\
$\alpha$ & 4 & $71.2 \pm 2.8$ & $277 \pm 9$ & $3.9 \pm 0.2$ \\
$\mathrm{C}$ & 12 & $129 \pm 5$ & $641 \pm 22$ & $\mathbf{5 . 0} \pm \mathbf{0 . 3}$ \\
\hline
\end{tabular}

(b) The total number of neutrons $n$ generated by one primary ion $\left({ }^{1} \mathrm{H},{ }^{2} \mathrm{H},{ }^{4} \mathrm{He}\right.$, or $\left.{ }^{12} \mathrm{C}\right)$ in a very thick lead target $(\Phi=20 \mathrm{~cm}$ and $L=60 \mathrm{~cm})$ and calculated with the model MCNPX2.7a. The last column gives the ratio of the neutron yields at energy $E_{\mathrm{kin}} / A=3.7 \mathrm{GeV}$ and at $E_{\mathrm{kin}} / A=1.0 \mathrm{GeV}$.

\begin{tabular}{lcccc}
\hline Ion & Mass $A$ & $\begin{array}{c}\text { Number of neutrons } n \text { at } \\
1 \mathrm{GeV} \text { per nucleon }\end{array}$ & $\begin{array}{c}\text { Number of neutrons } n \text { at } \\
3.7 \mathrm{GeV} \text { per nucleon }\end{array}$ & $\begin{array}{l}n \text { at }\left(E_{\text {kin }} / A=3.7 \mathrm{GeV}\right) \\
n \text { at }\left(E_{\text {kin }} / A=1.0 \mathrm{GeV}\right)\end{array}$ \\
\hline $\mathrm{H}$ & 1 & 23.5 & 73.4 & 3.12 \\
$\mathrm{H}$ & 2 & 48.0 & 118.9 & 2.48 \\
$\alpha$ & 4 & 77.5 & 201.6 & 2.60 \\
$\mathrm{C}$ & 12 & 134.8 & 494.3 & 3.67 \\
\hline
\end{tabular}

of reactions as just mentioned" (i.e., in agreement with wellaccepted standard models). The results reported in $[1,2]$ show evidence that secondary fragments excite target nuclei stronger than primary ions, thus producing more neutrons than expected from calculation. Findings from [1-3] are not in contradiction as will be shown [4]. It seems that as if unresolved problems arise only after an energetic limit that is barely approached in the $1 \mathrm{GeV} / \mathrm{u}{ }^{238} \mathrm{U}+\mathrm{Fe}$ experiment. This may become an important issue for high intensity, high energy heavy-ion accelerators presently under construction. One essential aspect of this construction is the consideration of all aspects of radiation protection for the operation of these machines with respect to

(i) workers in the laboratories,

(ii) materials close to the beam line and target areas,

(iii) and —not the least—-the surrounding environment.

The aim of this paper is to concentrate on the experimentally known facts which may serve as benchmarks for any radiation protection model. Two major topics will be considered.

(1) The neutron emission from thick targets irradiated with ions in the energy range of $1 \mathrm{GeV} \leq E_{\text {kin }} \leq$ $44 \mathrm{GeV}$ at the JINR in Dubna (Russia) and its influence on radiation protection.

(2) The experimental spallation mass-yields produced in a $20 \mathrm{~cm}$ thick $\mathrm{Cu}$ target in the irradiation with $72 \mathrm{GeV}$ ${ }^{40} \mathrm{Ar}$ at the LBNL in Berkeley (USA). Calculations with modern code MCNPX 2.7a [5] are compared with experiments demonstrating that secondaries interact with target nuclei stronger than primaries. The corresponding neutron emission in the irradiation was measured to be large, however, quantitative results have not been published.
A key question in all investigations is the determination of the total number of neutrons produced in a thick target by a single ion with a well-defined primary energy. A target is considered as being thick when a large fraction of secondary particles induce additional interactions within this target.

\section{Radiation Protection Studies at JINR, Dubna, Russia}

2.1. Direct Neutron Measurements from a Thick Pb Target at the Synchrophasotron Accelerator. In an early experiment, a very consistent measurement of the numbers of neutrons emitted from a thick $\mathrm{Pb}$ target $(\Phi=20 \mathrm{~cm}$ and $L=60 \mathrm{~cm})$ was carried out in irradiations with a large variety of ions available at the Synchrophasotron at the JINR in Dubna (Russia) by Vasil'kov et al. [11]. The essential experimental results are presented in Table 1(a), together with calculations in Table 1(b). One observes for proton irradiations at kinetic energies $E(p)=1 \mathrm{GeV}$ and $E(p)=3.7 \mathrm{GeV}$ a consistent and well-understood behaviour. The number of neutrons per $\mathrm{GeV}$ decreases slightly with increasing energy. However, one observes an unexpected result for heavy ions up to mass 12: The experimental values at $3.7 \mathrm{AGeV}$ are up to $50 \%$ larger than results from model calculations. One should remember that individual neutrons were determined by counting in an LSC unit.

A recent publication by Yurevich et al. [12] reports on the direct measurements of the total number of neutrons emitted from lead targets of various configurations in proton irradiations in the energy range $(1 \mathrm{GeV}<E(p)<3.7 \mathrm{GeV})$. The authors used various experimental techniques, including TOF and $\mathrm{Pb}(p, \mathrm{xn})$, to obtain the total number of emitted neutrons. They also investigated the same thick $\mathrm{Pb}$ target as the one employed in [11]. The observed neutron numbers 
per proton for the same target as shown in Table 1(a) are $(26 \pm 4)$ at $1 \mathrm{GeV}$ and $(76 \pm 7)$ at $3.7 \mathrm{GeV}$, which is in fair agreement with the results from [11].

\subsection{Radiation Protection and Indirect Measurements of Neu-} trons Produced by (1.0-1.5) GeV Protons at the Nuclotron Accelerator. A recent publication [6] from experiments at the Nuclotron accelerator in JINR describes measurements of the neutron dose from $1 \mathrm{GeV}$ protons around two thick $\mathrm{Pb}$ target assemblies, called "Gamma-2" and "Energy plus Transmutation" $(E+T)$. The neutron dose measurements were carried out close to the targets and in addition behind a $1.0 \mathrm{~m}$ thick concrete shielding wall of the experimental setups as shown in Figure 1.

The target system "Gamma-2" (for details see Figure 2 and Section 2.3 below) had been used earlier in the same experimental location of the Laboratory for high energy (JINR, Dubna) for heavy ion irradiations using the Synchrophasotron accelerator. Thus, one can compare the results from the present-day neutron dose experiments with earlier irradiations with relativistic heavy ions a decade ago using the same "Gamma-2" target.

The $\mathrm{Pb}$ core in the "Energy plus Transmutation" $(E+T)$ target has a diameter of $8.4 \mathrm{~cm}$ and a length of $45 \mathrm{~cm}$, and it is surrounded by a blanket of $206.4 \mathrm{~kg}$ natural uranium plus also a massive neutron shield. A detailed description can be found in $[6,13-15]$.

The neutron dose measurements were carried out with solid state nuclear track detectors (SSNTD's) by Fragopoulou et al. [6]. Their experimental techniques allow to obtain separate results for

(i) low-energy neutrons with $E(n)<1 \mathrm{eV}$,

(ii) epithermal neutrons with $1 \mathrm{eV}<E(n)<10 \mathrm{keV}$, and

(iii) intermediate-fast neutrons with $0.3 \mathrm{MeV}<E(n)<$ $3 \mathrm{MeV}$.

The actual neutron ambient dose equivalent in units of Sievert (Sv) was calculated using experimental conversion factors. The results are shown in Table 2:

The agreement between experiment and calculation is fine within uncertainties for these two target systems and in this energy range. The calculation for the "Gamma-2" target gave 15 neutrons per $1.0 \mathrm{GeV}$ proton which is smaller than the corresponding number in Table $1(\mathrm{a})$ as the $\mathrm{Pb}$ target in Gamma-2 was smaller than Vassil'kov's target.

A further detailed analysis of the fission rate inside the massive uranium blanket for the $(E+T)$ system has been carried out in [15]. The authors used Monte Carlo code MCNPX 2.6C and showed that the experimental fission rates are only about $(22 \pm 14) \%$ larger than the calculated ones.

2.2.1. Neutron Dose in the Vincinity of the Target. The intermediate-fast neutron dose around the $(E+T)$ target with its massive uranium blanket around a thick lead target is larger than around "Gamma-2", however, the thermalepithermal neutron dose is larger at "Gamma-2", due to the paraffin moderator around this target (see Table 2).

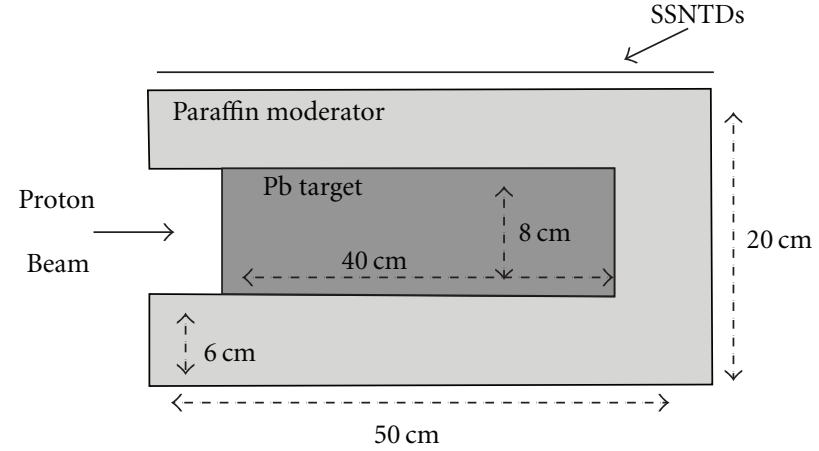

(a)

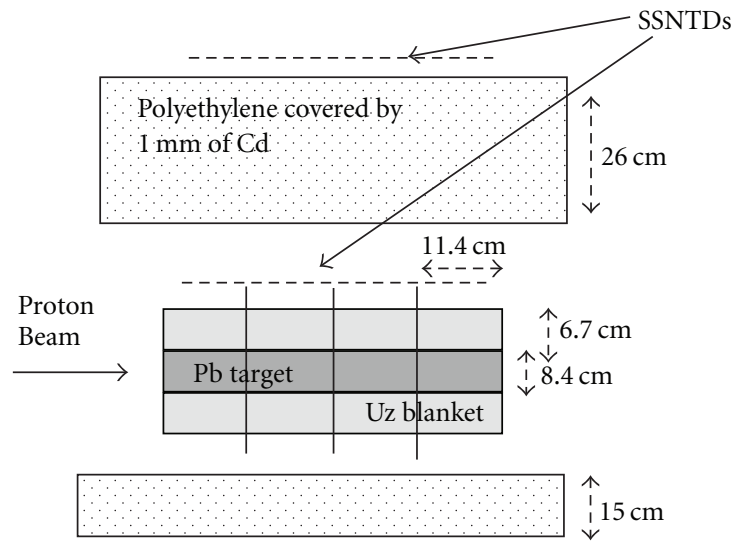

(b)

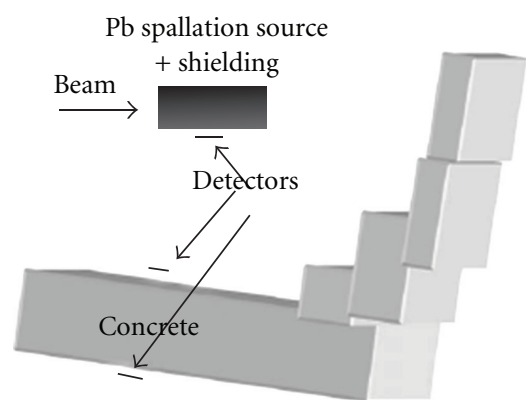

(c)

FIgURE 1: The spallation sources used in JINR in Dubna, Russia: (a) "Gamma-2" target, (b) "Energy plus Transmutation" $(E+T)$ assembly. The term "Uz blanket" stands for the uranium blanket surrounding the $\mathrm{Pb}$ target. (c) This diagram illustrates the positions of the spallation sources, the concrete shielding wall, and the locations of the SSNTDs (solid state nuclear track detectors) that serve to determine the neutron ambient dose equivalent. Distances can be estimated from the thickness of the concrete wall which is $1.00 \mathrm{~m}$ (Figure taken from [6]).

2.2.2. Neutron Dose behind $1 m$ of Concrete. The "Gamma-2" target produced a considerable thermal neutron dose behind the concrete wall. The irradiation lasted 11 hours with a total fluence of $10^{13}$ protons of $1 \mathrm{GeV}$ on target, corresponding to an average of $2.5 * 10^{8}$ protons $/ \mathrm{sec}$. The experimental neutron ambient dose equivalent behind the concrete wall was $37 \mu \mathrm{Sv} / \mathrm{h}$ [6], which is too much to be tolerated by humans. The ICRP 66 (International Commission on Radiological 


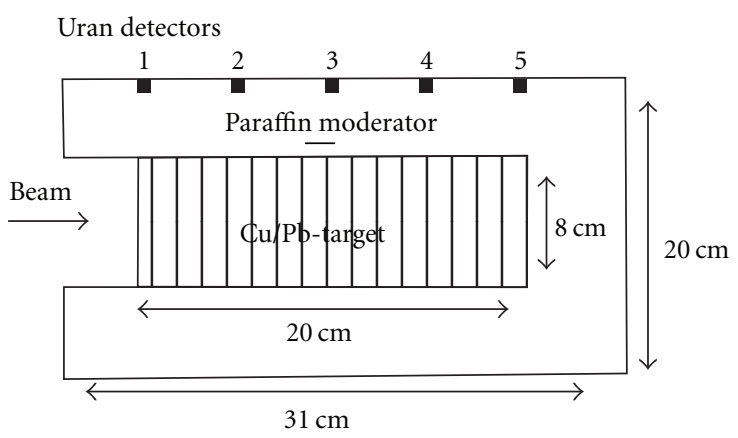

(a)

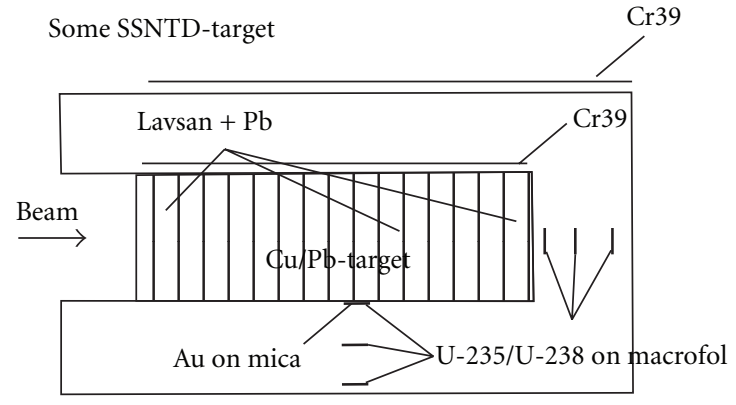

(b)

Lanthan detectors
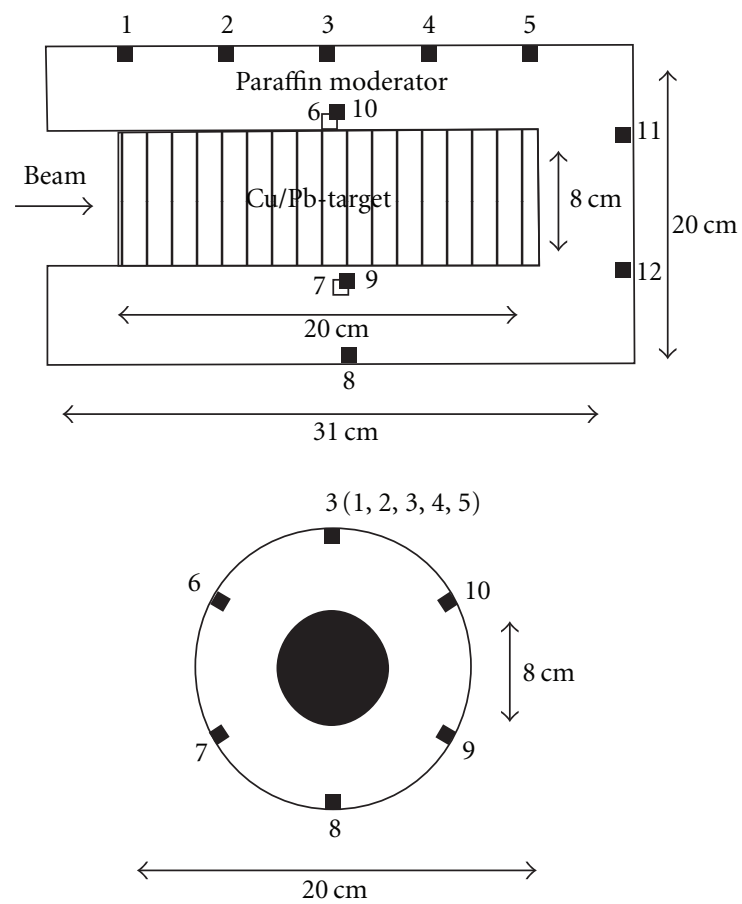

(c)

Figure 2: The GAMMA-2 target (Since 2007, GAMMA-2 has been an IAEA benchmark target for transmutation studies, see text and [710]). (a) Positions for uranium sensors, (b) positions of lanthanum sensors, (c) positions of various SSNTD sensors.

TABLE 2: Experimental neutron ambient dose equivalent from the irradiation of a Pb target in "Gamma-2" and "Energy plus Transmutation" $(E+T)$ with $10^{13}$ protons and a comparison with model calculations [6].

\begin{tabular}{lccc}
\hline Target and position of SSNTD & $\begin{array}{c}\text { Thermal-epithermal neutron dose } \\
\text { Experiment }\end{array}$ & Calculation & $\begin{array}{c}\text { Intermediate-fast neutron dose } \\
\text { Experiment }\end{array}$ \\
\hline Gamma-2, (at $1 \mathrm{GeV}$ ) close to target & $610 \pm 30 \mathrm{mSv}$ & - & $8000 \pm 3000 \mathrm{mSv}$ \\
Gamma-2, behind $1 \mathrm{~m}$ concrete & $0.411 \pm 0.114 \mathrm{mSv}$ & $0.375 \mathrm{mSv}$ & $<0.05 \mathrm{mSv}$ \\
$E \& T$, (at $1.5 \mathrm{GeV}$ ) close to target & $160 \pm 30 \mathrm{mSv}$ & - & $17000 \pm 4000 \mathrm{mSv}$ \\
$E+T$, behind $1 \mathrm{~m}$ concrete & $<0.0015 \mathrm{mSv}$ & $0.0013 \mathrm{mSv}$ & $<0.05 \mathrm{mSv}$ \\
\hline
\end{tabular}

Protection, Recommendation No. 66) recommends that for a position outside the concrete shielding of accelerators in "controlled areas," a dose should not exceed $10 \mu \mathrm{Sv} / \mathrm{h}$. Therefore, the Health Physics Department of JINR requested the scientists to stay at least $50 \mathrm{~m}$ away from the experimental area during irradiation. For irradiations of the $(E+T)$ target, similar rules applied, but the radiation level outside the experimental area was considerably smaller due to the additional neutron shield provisions around the $\mathrm{Pb} / \mathrm{U}$ target. 
TABLE 3: $B\left({ }^{140} \mathrm{La}\right)$-values on the "Gamma-2" Pb target, irradiated with protons at the Nuclotron [9] and compared with different model calculations.

\begin{tabular}{|c|c|c|c|c|}
\hline \multirow{2}{*}{ Proton energy + Target } & \multirow{2}{*}{ Experiment: $B\left({ }^{140} \mathrm{La}\right) 10^{-5}\left[\mathrm{~g}^{-1} *\right.$ proton $\left.^{-1}\right]$} & \multicolumn{3}{|c|}{ Calculation: neutrons/proton $(n / p)$} \\
\hline & & MCNPX 2.7a & LAHET [8] & $\mathrm{DCM}[8]$ \\
\hline $1.0 \mathrm{GeV}+\mathrm{Pb}$ & $4.69 \pm 0.32$ & 15.0 & 15.3 & 17.4 \\
\hline $2.0 \mathrm{GeV}+\mathrm{Pb}$ & $8.86 \pm 0.62$ & 26.4 & - & - \\
\hline $3.7 \mathrm{GeV}+\mathrm{Pb}$ & $11.35 \pm 0.80$ & 43.0 & 38.7 & 43.9 \\
\hline Ratio $2.0 \mathrm{GeV} / 1.0 \mathrm{GeV}$ & $1.89 \pm 0.19$ & 1.76 & - & - \\
\hline Ratio $3.7 \mathrm{GeV} / 1.0 \mathrm{GeV}$ & $2.5 \pm 0.2$ & 2.87 & 2.52 & 2.52 \\
\hline
\end{tabular}

Further experiments measuring the neutron dose equivalent under well-defined conditions during the irradiation with heavy ions onto thick targets are necessary with relativistic ions like ${ }^{2} \mathrm{H},{ }^{4} \mathrm{He}$, and ${ }^{12} \mathrm{C}$. Such irradiations had been carried out a decade ago using the "Gamma-2" target at the Synchrophasotron, however, without any quantitative measurements of the neutron ambient neutron dose equivalent outside the concrete shielding. In this paper, a "postfactum" estimate of the corresponding neutron ambient dose equivalent outside the concrete shielding is presented.

2.3. Neutron Emission from the "Gamma-2" Target Irradiated with Protons at the Nuclotron and Heavy Ions $\left({ }^{2} \mathrm{H},{ }^{4} \mathrm{He}\right.$, and $\left.{ }^{12} C\right)$ at the Synchrophasotron. The comparison of the neutron emission from the "Gamma-2" target irradiated with heavy ions at the Synchrophasotron accelerator and with protons at the Nuclotron accelerator will allow the intercalibration of experimental results from both accelerators. Figure 2 shows the detailed lay-out of the "Gamma-2" target. It consists of a metallic core of either $20 \mathrm{Cu}$ or $20 \mathrm{~Pb}$ disks $(1 \mathrm{~cm}$ thick, $8 \mathrm{~cm}$ diameter) and it is surrounded by a $6 \mathrm{~cm}$ thick paraffin moderator. The moderator contains grooves for plastic vials containing $1 \mathrm{~g}$ of La or $\mathrm{U}$ for radiochemical studies.

The "Gamma-2" target allows two-parameter experiments:

(1) In the irradiation with relativistic ions onto the metallic core, all kinds of spallation products are produced inside the metallic disks. These spallation products can be determined with standard radiochemical techniques after the irradiation.

(2) Spallation neutrons are simultaneously produced, which enter the paraffin. These neutrons are partially moderated, with many neutrons even reaching the thermal regime. All neutrons induce $(n, \gamma)$ and other reactions in various sensors. Details are given in $[1,2,7-10]$, only a short description will be given here. Using the lanthanum sensor, which is monoisotopic stable ${ }^{139} \mathrm{La}$, one can study the neutron capture reaction

$$
{ }^{139} \mathrm{La}(n, \gamma){ }^{140} \mathrm{La} \longrightarrow\left(\beta \text {-decay, } T_{1 / 2}=40.28 \text { hours }\right) .
$$

From the $\gamma$-ray emission rate of ${ }^{140} \mathrm{La}$ a production rate, called "breeding rate" $B\left({ }^{140} \mathrm{La}\right)$, can be calculated which is defined as

$$
B\left({ }^{140} \mathrm{La}\right)=\frac{\text { (number of produced } \left.{ }^{140} \mathrm{La} \text { atoms }\right)}{\left[\left(1 \mathrm{~g}^{139} \mathrm{La}\right) *(1 \text { primary ion })\right]} .
$$

In a similar manner, one can measure $B\left({ }^{239} \mathrm{~Np}\right)$ from the study of the reaction $\left[{ }^{238} \mathrm{U}(n, \gamma){ }^{239} \mathrm{U} \rightarrow{ }^{239} \mathrm{~Np}\right]$. For this comparative analysis, results measured for proton interactions at the Nuclotron in Table 3 and for heavy ion interactions at the Synchrophasotron in Table 4 using the same "Gamma-2" Pb target are shown.

Table 3 allows the following conclusions:

(i) The recent experimental values of $B\left({ }^{140} \mathrm{La}\right)$ ratios obtained for (1.0-3.7) $\mathrm{GeV}$ proton irradiation are in fine agreement with model calculations. Details of the $B\left({ }^{140} \mathrm{La}\right)$ distribution on top of the "Gamma-2" $\mathrm{Pb}$ target with MCNPX 2.7a calculations for $1.0 \mathrm{GeV}$ and $2.0 \mathrm{GeV}$ protons reveal good agreement between experiment and calculation [16].

(ii) The $B\left({ }^{140} \mathrm{La}\right)$ ratios between $(3.7 \mathrm{GeV} / 1.0 \mathrm{GeV})$ and $(2.0 \mathrm{GeV} / 1.0 \mathrm{GeV})$ agree with model calculations.

During the last decade of the operation of the Synchrophasotron until about the year of 2000, extended irradiations of "Gamma-2" targets with ${ }^{2} \mathrm{H}-,{ }^{4} \mathrm{He}$-, and ${ }^{12} \mathrm{C}$-beams in the range of total energies from $3 \mathrm{GeV}$ up to $44 \mathrm{GeV}$ were carried out $[7,8]$ where the metallic target core was copper or lead. Radiochemical sensors, such as stable lanthanum (see (1)) and natural uranium were irradiated and $B\left({ }^{140} \mathrm{La}\right)$ and $B\left({ }^{239} \mathrm{U}\right)$ values were obtained. Results of irradiations with ${ }^{2} \mathrm{H}-{ }^{4} \mathrm{He}$-, and ${ }^{12} \mathrm{C}$-ions onto "Gamma-2" targets at the Synchrophasotron are shown in Figures 3 and 4.

The resulting distributions for ${ }^{2} \mathrm{H}-,{ }^{4} \mathrm{He}-$, and $18 \mathrm{GeV}$ ${ }^{12} \mathrm{C}$-irradiations are surprisingly similar, irrespective of the projectile element and energy. In the $44 \mathrm{GeV}^{12} \mathrm{C}$ irradiation, however, one observes a drastic increase in the production of ${ }^{140} \mathrm{La}$ and ${ }^{239} \mathrm{~Np}$.

Similar results are observed in experiments using a $\mathrm{Cu}-$ core in "Gamma-2." The results are shown in Figure 4, where the average $B$-value for the investigation in five La- or $\mathrm{U}$ sensors on top of the moderator is given [7]. Again, for $44 \mathrm{GeV}^{12} \mathrm{C}$ irradiations, one observes a strong increase in $B$ value, whereas at lower total bombarding energies, $B$-values are grouping around significantly lower values. 
TABLE 4: Neutron fluences measured as $B\left({ }^{140} \mathrm{La}\right)$ on "Gamma-2" target in irradiations with ${ }^{2} \mathrm{H},{ }^{4} \mathrm{He}$, and ${ }^{12} \mathrm{C}$ at the Synchrophasotron [7].

\begin{tabular}{lccc}
\hline Target system & $\mathrm{B}\left({ }^{140} \mathrm{La}\right) 10^{-5}\left[\right.$ atoms $\left.* \mathrm{~g}^{-1} * \mathrm{ion}^{-1}\right]$ & \multicolumn{2}{c}{$B(3.7 \mathrm{AGeV}+\mathrm{Pb}) / B(1.5 \mathrm{AGeV}+\mathrm{Pb})$} \\
& & Experiment & $1.08 \pm 0.07$ \\
\hline $3.0 \mathrm{GeV}^{2} \mathrm{H}+\mathrm{Pb}$ & $68.1 \pm 4.8$ & & 1.69 \\
$7.4 \mathrm{GeV}^{2} \mathrm{H}+\mathrm{Pb}$ & $73.5 \pm 5.2$ & $1.13 \pm 0.07$ & 1.90 \\
$6 \mathrm{GeV}^{4} \mathrm{He}+\mathrm{Pb}$ & $81.0 \pm 5.7$ & & \\
$14.7 \mathrm{GeV}^{4} \mathrm{He}+\mathrm{Pb}$ & $91.4 \pm 6.3$ & $2.30 \pm 0.14$ & 1.99 \\
$18 \mathrm{GeV}^{12} \mathrm{C}+\mathrm{Pb}$ & $116 \pm 8$ & \\
$44 \mathrm{GeV}^{12} \mathrm{C}+\mathrm{Pb}$ & $266 \pm 19$ & \\
\hline
\end{tabular}

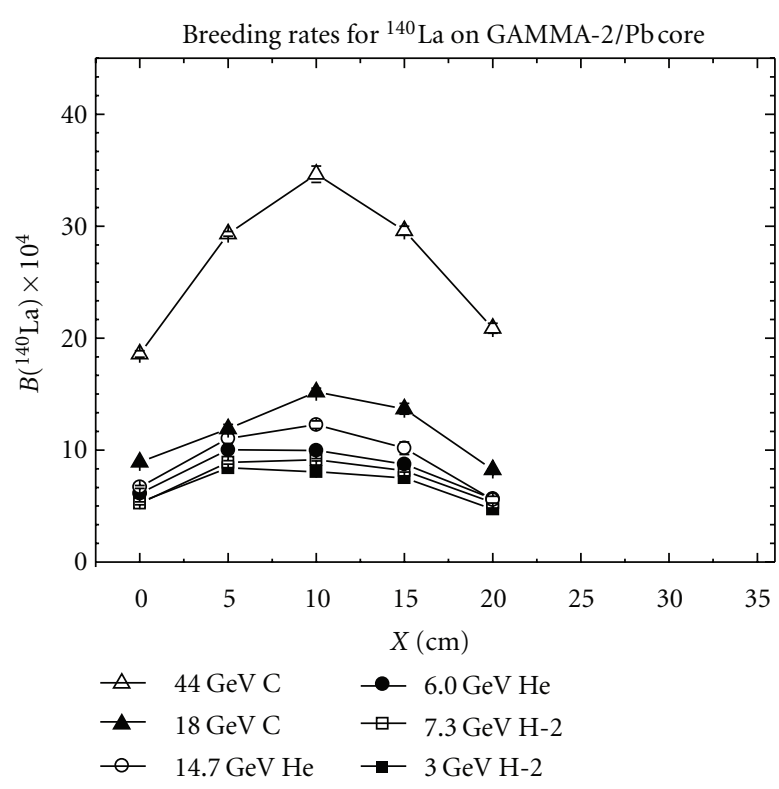

(a)

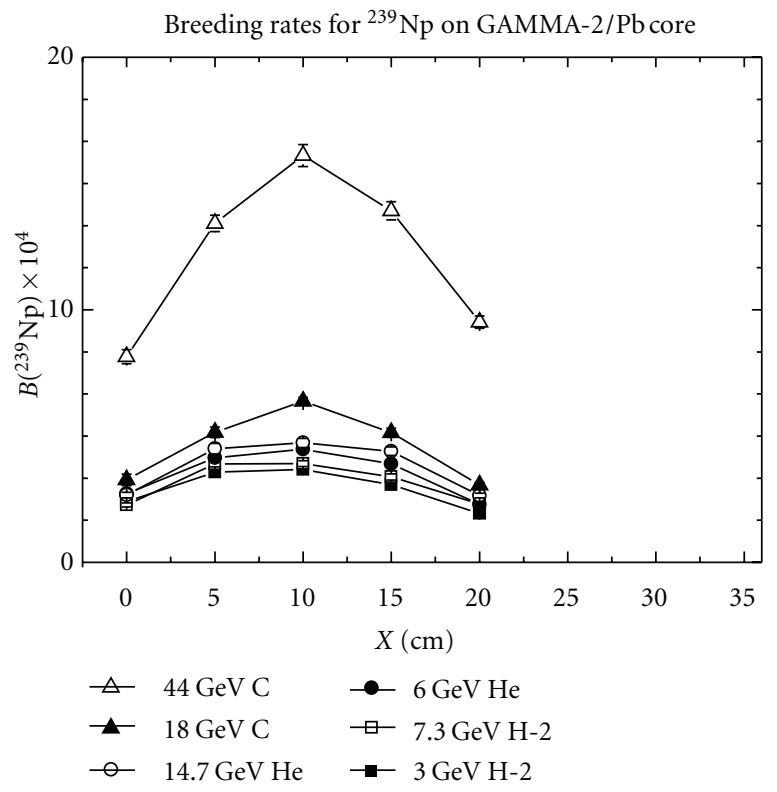

(b)

Figure 3: Breeding rates $B\left({ }^{140} \mathrm{La}\right)$ and $B\left({ }^{239} \mathrm{~Np}\right)$ in irradiations with relativistic ${ }^{2} \mathrm{H},{ }^{4} \mathrm{He}$, and ${ }^{12} \mathrm{C}$ onto a Pb core in "Gamma-2". Results are given for 5 sensors on top of the paraffin moderator [7].

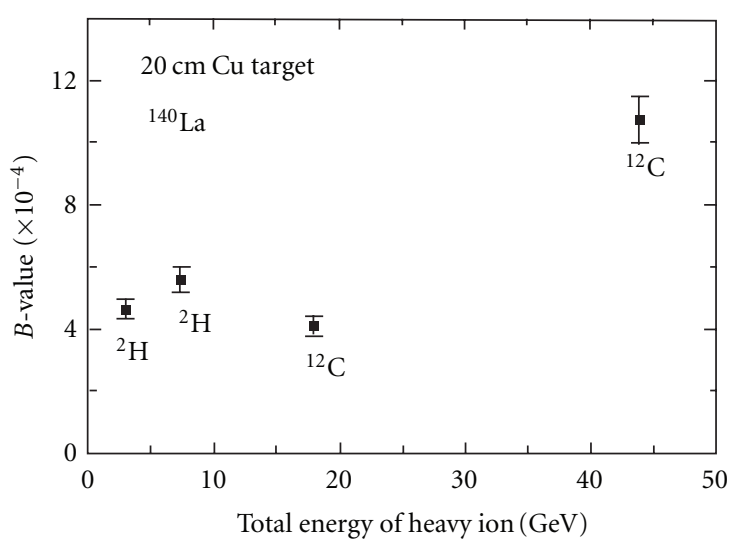

(a)

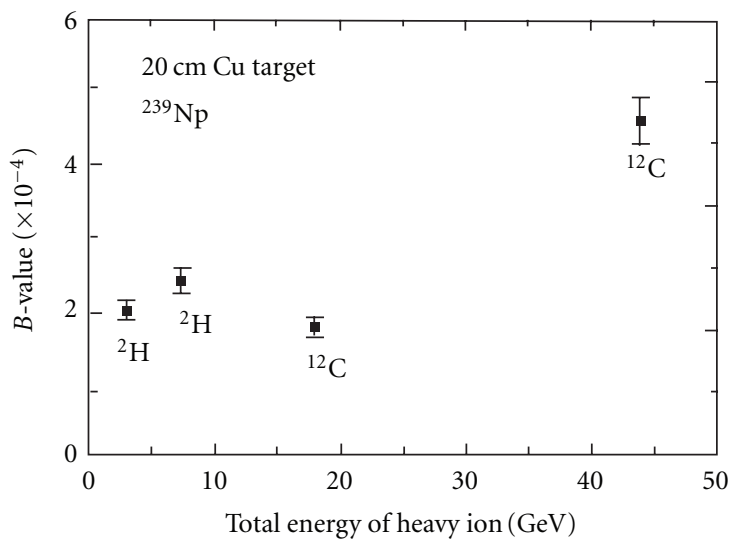

(b)

FIgURE 4: Breeding rates $B\left({ }^{140} \mathrm{La}\right)$ and $B\left({ }^{239} \mathrm{~Np}\right)$ in the irradiation with ${ }^{2} \mathrm{H}$ and ${ }^{12} \mathrm{C}$ onto a Cu core in the centre of "Gamma-2". $B$-values are averages from 5 sensors. (This figure is taken from [7]). 
TABLE 5: Estimated neutron ambient doses (for $2.5 * 10^{8}$ ions/s) in irradiations with $44 \mathrm{GeV}{ }^{12} \mathrm{C}$, as based on recent experiments with $1 \mathrm{GeV}$ protons onto a "Gamma-2" $\mathrm{Pb}$ target. The calculated neutron production rate in neutrons per ion is taken as the basis for calculation of the last column.

\begin{tabular}{lcccc}
\hline Beam + target & $B\left({ }^{140} \mathrm{La}\right)\left(* 10^{-5} / \mathrm{g} /\right.$ ion $) * * *$ & $\begin{array}{c}\text { Neutron dose in } \mu \text { Sv/h } \\
\text { behind } 1 \mathrm{~m} \text { of concrete }\end{array}$ & $\begin{array}{c}\text { Calculated neutrons } \\
(n / \text { ion })\end{array}$ & $n /$ ion \\
\hline $1 \mathrm{GeV} \mathrm{p}+\mathrm{Pb}$ & $4.69 \pm 0.32$ & $36.5 \pm 2.1[12]$ & $16 \pm 1^{*}$ & $2.3 \pm 0.3$ \\
$44 \mathrm{GeV}^{12} \mathrm{C}+\mathrm{Pb}$ & $266 \pm 19$ & 2070 (estimated) & $275 \pm 10^{*}$ & $7.6 \pm 0.8$ \\
$44 \mathrm{GeV}{ }^{12} \mathrm{C}+\mathrm{Cu}$ & $108 \pm 8$ & 840 (estimated) & $115 \pm 10^{*}$ & $7.4 \pm 1.0$ \\
$44 \mathrm{GeV}{ }^{12} \mathrm{C}+\mathrm{U} / \mathrm{Pb}$ & $500^{+}$ & 3890 (estimated) & $726^{* *}$ & 5.5 \\
$72 \mathrm{GeV}{ }^{40} \mathrm{Ar}+\mathrm{Cu}$ & Not measured & Very large & $250^{* *}$ & - \\
\hline
\end{tabular}

${ }^{+} B\left({ }^{140} \mathrm{La}\right)$-value estimated from the comparison of experiments on "Gamma -2" with $\mathrm{Pb}$ target and "Gamma-2" with $\mathrm{Pb} / \mathrm{U}$ target as described in $[8,10,19]$. * Based on DCM/CEM, LAHET $([8,20])$ and MCNPX 2.7a (this work).

$* *$ Based on MCNPX 2.7a (this work).

$* * * B\left({ }^{140} \mathrm{La}\right)$ is the average value $[7,9]$ from five La-sensors on top of the moderator (see Figure 2).

Neutron induced interactions were studied by this collaboration over a wide energy range: Wang et al. [17] studied the integral neutron energy spectra emitted from "Gamma2" with the nuclear emulsion technique. They measured secondary neutrons with energies up to $1 \mathrm{GeV}$. Their results are complementary to the work of Yordanov et al. [3], who studied high energy neutron spectra behind $20 \mathrm{~cm}$ thick iron targets with counter techniques.

A summary of $B\left({ }^{140} \mathrm{La}\right)$-values, originating from the capture of low-energy neutrons, measured in ${ }^{2} \mathrm{H},{ }^{4} \mathrm{He}$, and ${ }^{12} \mathrm{C}$ ion irradiations is given in Table 4. The experimental ratios of $B$-values at (3.7 AGeV/1.5 AGeV) are

(i) $(1.1 \pm 0.1)$ for ${ }^{2} \mathrm{H}$ and ${ }^{4} \mathrm{He}$ induced reactions, and

(ii) $(2.3 \pm 0.2)$ for ${ }^{12} \mathrm{C}$ irradiations, which is significantly higher.

The large $B\left({ }^{140} \mathrm{La}\right)$-value for $44 \mathrm{GeV}$ irradiations is again an indication of something different, already observed in $[1,2]$ and termed there as "unresolved problem." A similar observation was found earlier by Brandt [18]. In the irradiation of a large $\mathrm{Pb}$ block with $3.7 \mathrm{AGeV}$ ions from the Synchrophasotron, fine agreement between experiment and calculations for proton, deuteron, and alpha irradiations was observed. In the irradiation with $44 \mathrm{GeV}{ }^{12} \mathrm{C}$, however, $B\left({ }^{239} \mathrm{~Np}\right)=(15 \pm 5) * 10^{-4}$ (atoms per carbon ion per gram of $\mathrm{Np}$ ) was measured, which is about twice as large as calculated by Tolstov and rather similar to our result shown in Figure 3.

All evidences demonstrate that one needs additional experiments to study the neutron production in thick targets using heavy ions at high energies. In these future experiments, one may be confronted with nontrivial radiation protection problems. $1 \mathrm{GeV}$ protons on the "Gamma-2" $\mathrm{Pb}$ target lead to a large neutron dose behind the concrete shielding; therefore, one might expect much more severe radiation protection problems in irradiations with $44 \mathrm{GeV}^{12} \mathrm{C}$ beams.

If assuming that

(i) one uses the same experimental setup as shown in Figure 1, and

(ii) the "neutron ambient dose" behind the concrete shielding increases linearly with $B\left({ }^{140} \mathrm{La}\right)$-values that were measured on "Gamma-2" with $\mathrm{Pb}$ core at the Synchrophasotron, then one obtains estimated neutron ambient doses as given in Table 5.

The measured ambient neutron dose $(\mu \mathrm{Sv} / \mathrm{h})$ and the experimental transmutation rate $B\left({ }^{140} \mathrm{La}\right)$ in the interaction of $(1 \mathrm{GeV} p+\mathrm{Pb}$ target $)$ yielding a ratio $[(\mu \mathrm{Sv} / \mathrm{h}) /(n /$ ion $)]=$ $2.3 \pm 0.3$ are in agreement with recent calculations. For irradiation with $44 \mathrm{GeV}{ }^{12} \mathrm{C}$ onto a thick Gamma-2 target core, however, one estimates an average

$$
\left[\frac{\mu S v / h}{n / \text { ion }}\right]=(7.6 \pm 0.8),
$$

which is much larger and statistically significantly different from 2.3. This is a further indication that one may observe for large beam energies onto thick targets significantly higher than calculated neutron numbers. The neutron ambient doses behind the concrete shielding exceed significantly the radiation protection allowance for humans to stay near this area during the experiment. A further clarification of this problem can only be obtained with more experiments. Such experiments are needed to understand the underlying physics more accurately, as well as to supply more adequate radiation protection shielding data for thick-target irradiations.

\section{Thick Target Studies at LBNL, Berkeley, California}

Thick-target experiments at Lawrence Berkeley National Laboratory (LBNL) started around 1980 with the irradiation of two $\mathrm{Cu}$ disks in contact, with each disk having a thickness of $1 \mathrm{~cm}$ and a diameter of $8 \mathrm{~cm}$. The aim of such studies was the investigation of possible differences in nuclear interactions of relativistic secondary fragments in comparison with the relativistic primary ions as reviewed in $[1,2]$ and presented in Figures 5 and 6.

The ratio of nuclear interactions induced by primaries to those induced by secondaries is larger in the first $\mathrm{Cu}$ disk than in the second $\mathrm{Cu}$ disk. The study of experimental yield ratios of individual spallation products ${ }^{A} Z$ in the second $\mathrm{Cu}$ disk as compared with the first $\mathrm{Cu}$ disk reveals evidence for a different behaviour of secondary fragments as compared with the primary ions. 


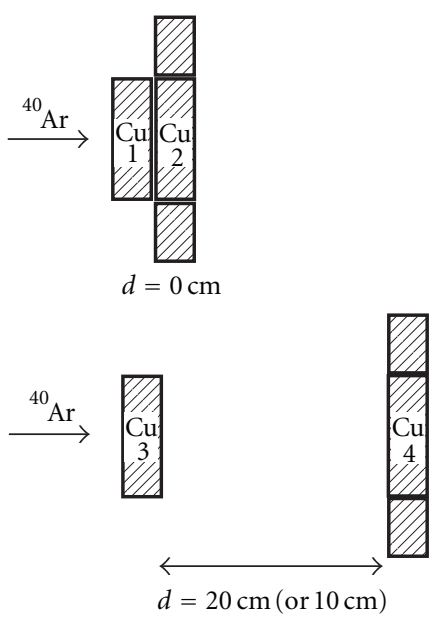

(a)

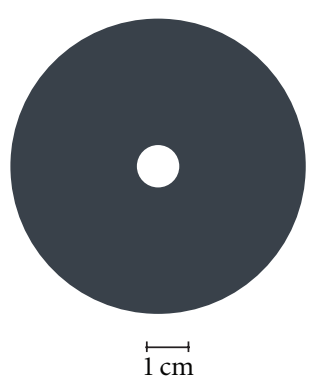

(b)

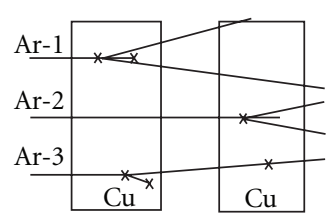

(c)
FIgURE 5: The original "two $\mathrm{Cu}$ disk experiments" in Berkeley showing the first evidence for unresolved problems $[1,2]$ in irradiations with $72 \mathrm{GeV}^{40} \mathrm{Ar}$ at the Bevalac accelerator (LBNL) after 1980. The original "two Cu disks" experiments were carried out from 1980 with relativistic ${ }^{40} \mathrm{Ar}$-ions at the Bevalac in Berkeley. (a) Schematic representation of the target set-up using two $\mathrm{Cu}$ disks and a surrounding guard ring around the second disk. Two configurations were irradiated: (i) (top): $0 \mathrm{~cm}$ distance between the disks $\left(R_{0}\right)$, (ii) (bottom): $20 \mathrm{~cm}$ distance between the disks $\left(R_{20}\right)$. (b) Autoradiographic negative picture of a $\mathrm{Cu}$ disk after an irradiation with $72 \mathrm{GeV}^{40} \mathrm{Ar}$ showing the well-focussed Ar beam in the centre. (c) Schematic representation of 3 different reaction paths. The path Ar-3 is of particular importance for the study of effects due to secondary fragments.

The ratio $R_{0}\left({ }^{A} Z\right)$ is defined for two Cu disks in contact $(d=0 \mathrm{~cm})$, where

$$
R_{0}\left({ }^{A} Z\right)=\frac{\text { Activity of }{ }^{A} Z \text { in second } \mathrm{Cu} \text { disk }}{\text { Activity of }{ }^{A} Z \text { in first } \mathrm{Cu} \text { disk }}
$$

activities are decay-corrected to the end of bombardment.

Figure 5 shows the experimental setup and the results are shown in Figure 6. Our focus will be on the $R_{0}$ results. Due to considerable production of relativistic secondaries, one observes for all spallation products $R_{0}(A)>1.00$. It is interesting to note two surprising features in Figure 6:

(i) $R_{0}$ for ${ }^{24} \mathrm{Na}$ is $R_{0}(24)=(1.50 \pm 0.02)$. This value is considerably larger, by at least $25 \%$, than all values based on various theoretical model calculations as has been discussed by Aleklett et al. [19] and in detail in $[1,2]$ : the production of ${ }^{24} \mathrm{Na}$ by secondaries is larger than that by primaries.

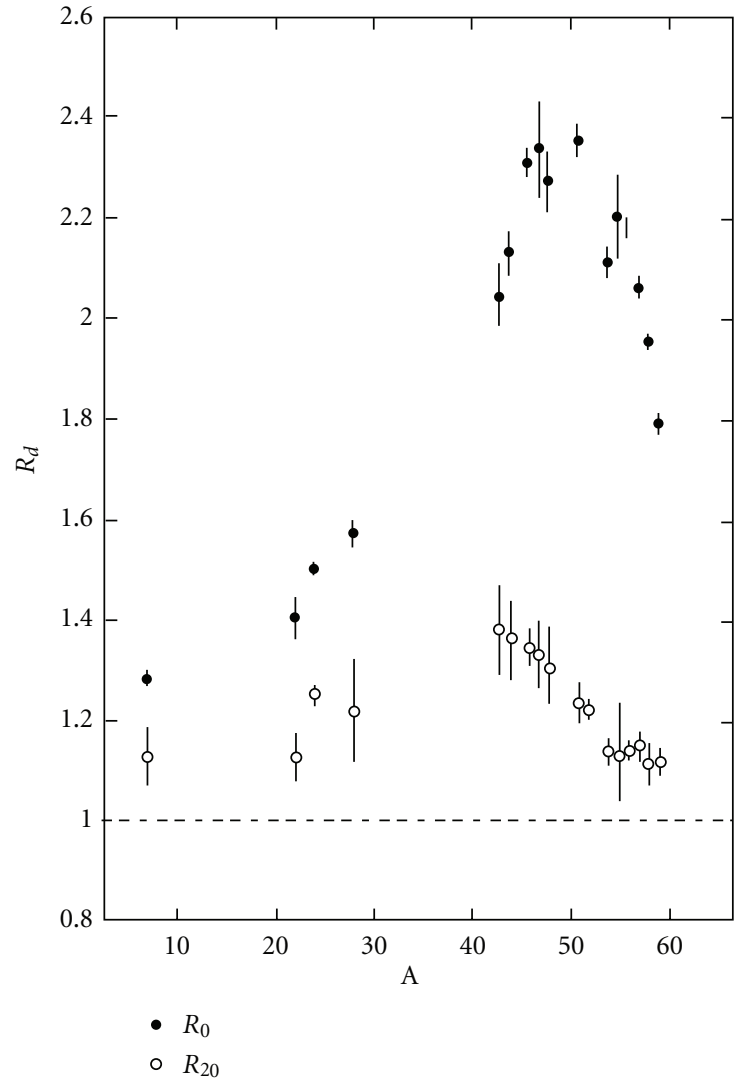

FIGURE 6: The original "two $\mathrm{Cu}$ disk experiments" in Berkeley showing the first evidence for unresolved problems [1,2] in irradiations with $72 \mathrm{GeV}^{40} \mathrm{Ar}$ at the Bevalac accelerator (LBNL) after 1980. $R_{d}$ ratios for reaction products ${ }^{A} Z$ measured in interactions of $72 \mathrm{GeV}^{40} \mathrm{Ar}$ with two $\mathrm{Cu}$ disks are defined as: (activity of nuclide ${ }^{A} Z$ downstream/activity of nuclide ${ }^{A} Z$ upstream). The distance between the two $\mathrm{Cu}$ disks is $d=0 \mathrm{~cm}$ for $R_{0}$ and $d=20 \mathrm{~cm}$ for $R_{20}$. These ratios can be determined very accurately.

(ii) One observes for product masses above $A=56$ a decrease in $R_{0}$ with increasing mass $A$. All theoretical interpretations have failed to describe this phenomenon.

The comparison of experimental results (see Figure 6) with the calculated $R_{0}(A)$ distribution using the MCNPX 2.7a code is shown in Figure 7 and reveals surprising results.

Some details of this comparison shall be emphasized

(i) For mass $A=7\left({ }^{7} \mathrm{Be}\right)$ and for masses $43 \leq A \leq 48$ the agreement is good.

(ii) The experimental production rate of the isotope ${ }^{24} \mathrm{Na}$ (as well as ${ }^{22} \mathrm{Na}$ and ${ }^{28} \mathrm{Mg}$ ) is significantly larger than models calculate. (Region 1 around $A=24$ ).

(iii) Above $A=56$ experimental $R_{0}$ decreases with rising $A$ whereas an increase in $R_{0}$ with rising $A$ is theoretically predicted. (Region 2 above $A=56$ ).

The results for Region 1 could correlate with the result seen in Region 2. One finds an excess of experimental cross 


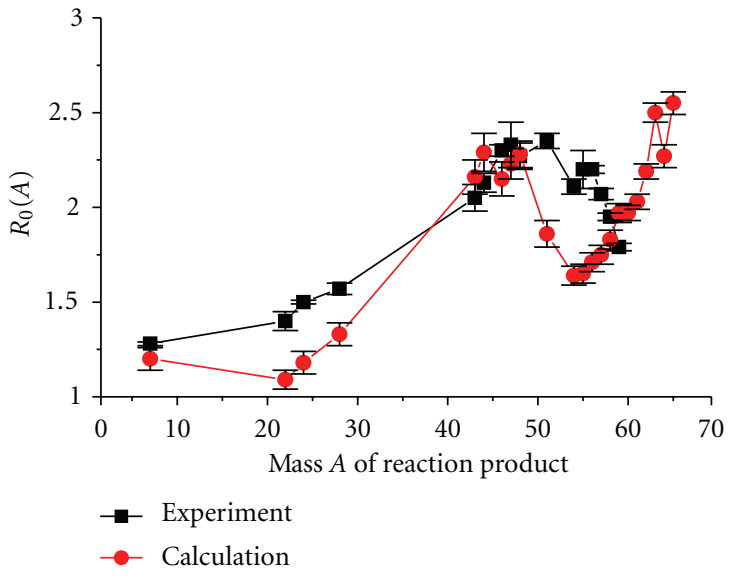

Figure 7: Comparison of the experimental and theoretical $R_{0}(A)$ distributions in the interaction of $72 \mathrm{GeV}^{40} \mathrm{Ar}$ with two $\mathrm{Cu}$ disks.

section in Region 1 whereas one misses cross-section in the second Cu disk just below the target mass in Region 2.

It may be useful to carry out further experiments to learn more about these phenomena from additional experimental approaches:

(i) One should measure $R_{0}$ for many nuclides close to the target mass but also for ${ }^{60} \mathrm{Co},{ }^{61} \mathrm{Co},{ }^{62} \mathrm{Zn}$, and ${ }^{64} \mathrm{Cu}$ in order to compare with Cumming et al.'s [20] data where production rates for these isotopes in thin $\mathrm{Cu}$ targets irradiated with $80 \mathrm{GeV}^{40} \mathrm{Ar}$ were determined.

(ii) Additionally, one should carry out neutron counting experiments using thick $\mathrm{Cu}$ targets having thicknesses $2 \mathrm{~cm} \leq T \leq 20 \mathrm{~cm}$ irradiated with $72 \mathrm{GeV}^{40} \mathrm{Ar}$ ions.

The experimental $R_{20}(A)$ distribution shown in Figure 6 is compared with the theoretical calculation using the MCNPX 2.7a code in Figure 8. The congruence between the theoretical fit and the experiment is remarkable. One observes only a slight experimental deficiency around masses $A=45$ and a slight experimental excess for ${ }^{24} \mathrm{Na}$.

The last issue of this paper is concerned with the radiochemical aspects in the study of a $20 \mathrm{~cm}$ thick $\mathrm{Cu}$ target (i.e., $20 \mathrm{Cu}$ disks of $1 \mathrm{~cm}$ thickness in contact) irradiated with $72 \mathrm{GeV}{ }^{40} \mathrm{Ar}$. In this irradiation at LBNL, a very strong neutron dose was registered even outside the experimental area of the Bevalac accelerator. However, quantitative neutron data about this event have never been released.

The $20 \mathrm{~cm}$ thick $\mathrm{Cu}$ target was designed as a twoparameter experiment:

(i) The determination of neutron production was in principle possible, however, no results of neutron measurements were ever published, as mentioned several times.

(ii) Nuclear reactions inside the $\mathrm{Cu}$ disks were actually studied, that is, spallation product yields in several $1 \mathrm{~cm} \mathrm{Cu}$ disks were determined, yielding information about nuclear interactions of relativistic ions inside the entire thick $\mathrm{Cu}$ target.

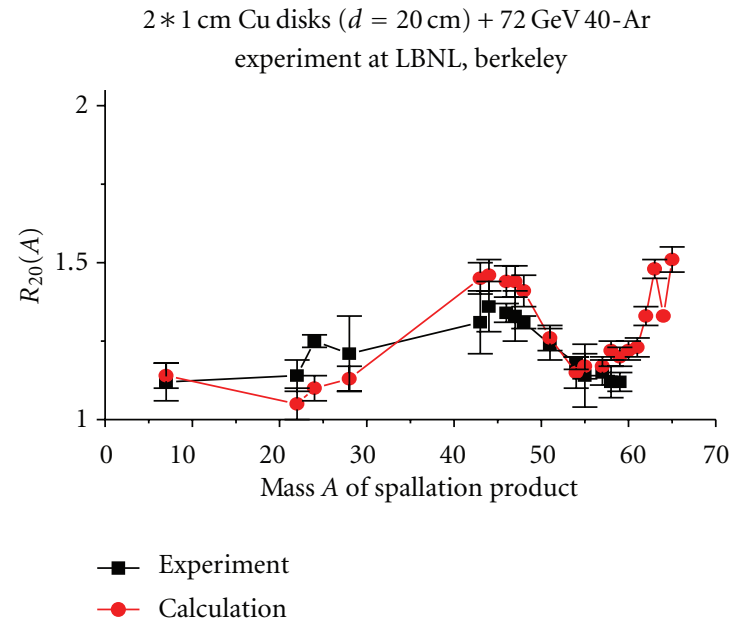

FIGURE 8: Comparison of the experimental $R_{20}(A)$ distribution and the MCNPX 2.7a calculation.

Both sets of information (neutron production rates plus spallation yields) are needed for a complete understanding of the reaction mechanism.

Some detailed experimental yield ratios $R_{i}\left({ }^{A} Z\right)$ for two typical spallation nuclides $\left({ }^{24} \mathrm{Na}\right.$ and $\left.{ }^{57} \mathrm{Ni}\right)$ in several $\mathrm{Cu}$ disks (number $=i$ ) as compared with the first $\mathrm{Cu}$ disk (number $=1$ ) will be discussed. The nuclide ${ }^{24} \mathrm{Na}$ was chosen as representative for "Region 1 " and ${ }^{57} \mathrm{Ni}$ as representative for "Region 2." The experimental yield ratios are compared with their calculated ratio using MCNPX 2.7a in Figure 7. Two nuclides appear to be of particular importance:

(i) The key isotope ${ }^{24} \mathrm{Na}$ (Region 1) is produced in the downstream $1 \mathrm{~cm}$ thick $\mathrm{Cu}$ disks $(I>1)$ definitely in larger yield than calculated by computer codes, including MCNPX 2.7a.

(ii) The isotope ${ }^{57} \mathrm{Ni}$ (Region 2 with $A>56$ ) is produced in the downstream $1 \mathrm{~cm}$ thick $\mathrm{Cu}$ disks $(I>1)$ with about the same yield as calculated by MCNPX 2.7a.

The following Figures 9 and 10 present the respective ratios for $R_{i}\left({ }^{A} Z\right)$-values, where $i$ is the number of the $\mathrm{Cu}$ disk within the $20 \mathrm{~cm} \mathrm{Cu}$ stack. The experimental ratios are compared with model calculations, experimental data tables are given in [21].

(i) ${ }^{24} \mathrm{Na}$ is produced more abundantly than calculated in every disk, just as in the " $2 \mathrm{~cm} \mathrm{Cu} \mathrm{disk"} \mathrm{experiment.}$

(ii) ${ }^{57} \mathrm{Ni}$ is produced a little less abundantly in this experiment as compared with calculation. This deficiency is observed in all $\mathrm{Cu}$ disks in the $20 \mathrm{~cm} \mathrm{Cu}$ target.

Repeating the argumentation presented for Figure 7, one can correlate the behaviour of ${ }^{24} \mathrm{Na}$ with the behaviour of ${ }^{57} \mathrm{Ni}$. One finds an excess in experimental cross section for ${ }^{24} \mathrm{Na}$ in all $\mathrm{Cu}$ disks as compared with calculation, and one misses experimental cross section in all $\mathrm{Cu}$ disks for ${ }^{57} \mathrm{Ni}$. This is continuing evidence for discrepancies that requests further experiments to measure product yields and 


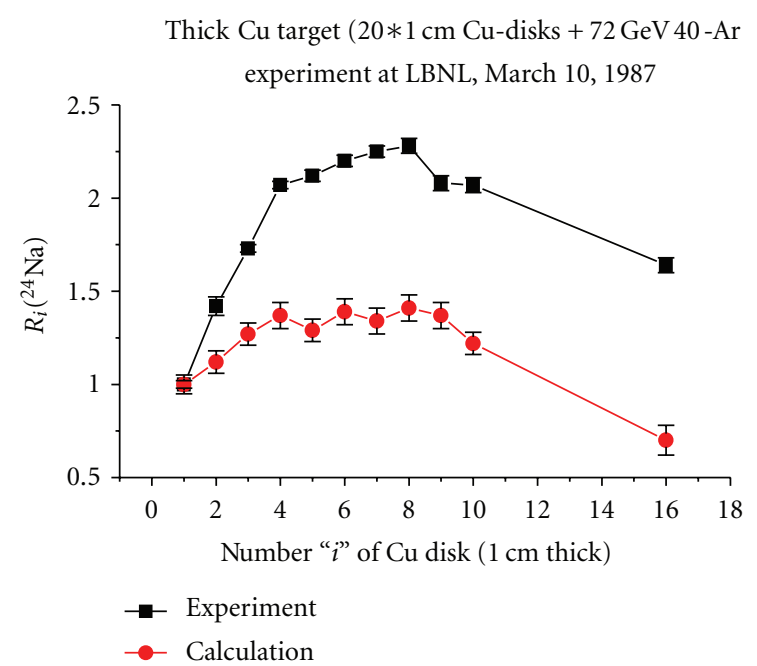

FIGURE 9: Comparison of the experimental $R_{i}\left({ }^{24} \mathrm{Na}\right)$ yields in the $20 \mathrm{~cm} \mathrm{Cu}$ stack with theoretical values from the computer code MCNPX 2.7a. $R_{i}\left({ }^{24} \mathrm{Na}\right)$ is the activity ratio of ${ }^{24} \mathrm{Na}$ in $\mathrm{Cu}$ disk number " $i$ " as compared with the first disk.

Thick $\mathrm{Cu}$ target $(20 * 1 \mathrm{~cm} \mathrm{Cu}$ disks $)+72 \mathrm{GeV} 40-\mathrm{Ar}$ experiment at LBNL, March 10, 1987

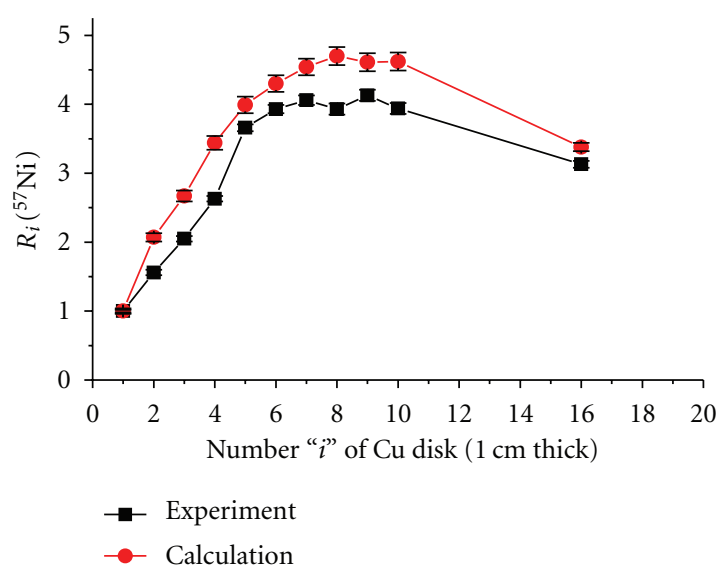

Figure 10: Comparison of the experimental $R_{i}\left({ }^{57} \mathrm{Ni}\right)$ yields in the $20 \mathrm{~cm} \mathrm{Cu}$ stack with theoretical values from the computer code MCNPX 2.7a. $R_{i}\left({ }^{57} \mathrm{Ni}\right)$ is the activity ratio of ${ }^{57} \mathrm{Ni}$ in $\mathrm{Cu}$ disk number " $i$ " as compared with the first disk.

additionally also the neutron production per ion in the reaction of $72 \mathrm{GeV}^{40} \mathrm{Ar}$ with a thick $\mathrm{Cu}$ target (or similar).

Another question to be asked is: what amount of "enhanced neutron production" can one expect in the reaction $\left(20 \mathrm{~cm} \mathrm{Cu}+72 \mathrm{GeV}{ }^{40} \mathrm{Ar}\right)$ as compared with the wellinvestigated reaction $\left(20 \mathrm{~cm} \mathrm{Cu}+44 \mathrm{GeV}^{12} \mathrm{C}\right)$ ? There exists only one indirect measure for the "enhanced nuclear destruction" ability of secondary fragments in thick copper targets, which is the measurement of $R_{0}\left({ }^{24} \mathrm{Na}\right)$ in "two $\mathrm{Cu}$ disk experiments" (Figures 5 and 6 ) for a large variety of projectile ions using several accelerators around the world. The result of such investigation is presented in Figure 11. It was shown in $[1,2]$ that there is a smooth relation between $R_{0}\left({ }^{24} \mathrm{Na}\right)$

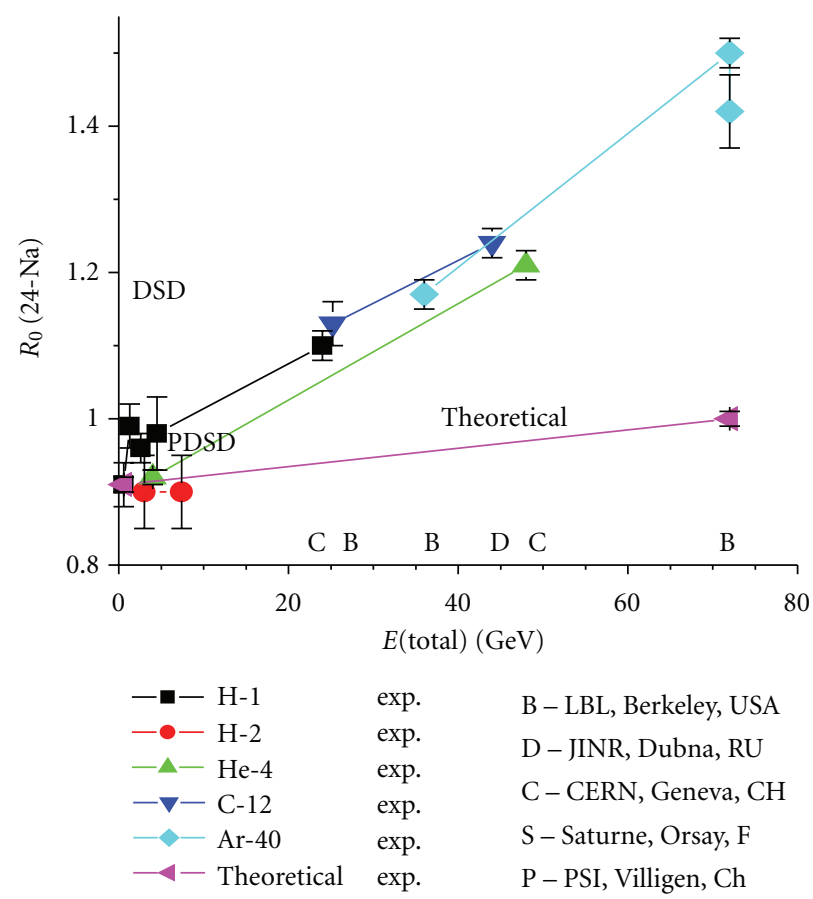

Figure 11: The ratio $R_{0}\left({ }^{24} \mathrm{Na}\right)$ as a function of total kinetic energy. The calculated "theoretical" line from $[1,2]$ is given for comparison.

and the energy of the ion when the experimental $R_{0}\left({ }^{24} \mathrm{Na}\right)$ values are plotted with respect to the total ion energy $E_{\text {kin }}$, irrespective of the ion. Some of those experimental ratios for ${ }^{24} \mathrm{Na}$ production are

(i) $1.5 \mathrm{GeV}{ }^{1} \mathrm{H}$ onto two $\mathrm{Cu}$ disks yield $R_{0}\left({ }^{24} \mathrm{Na}\right)=$ $0.99 \pm 0.03$;

(ii) $44 \mathrm{GeV}{ }^{12} \mathrm{C}$ onto two $\mathrm{Cu}$ disks yield $R_{0}\left({ }^{24} \mathrm{Na}\right)=$ $1.24 \pm 0.02$

(iii) $72 \mathrm{GeV}{ }^{40} \mathrm{Ar}$ onto two $\mathrm{Cu}$ disks yield $R_{0}\left({ }^{24} \mathrm{Na}\right)=$ $1.50 \pm 0.02$

The increase in $R_{0}\left({ }^{24} \mathrm{Na}\right)$ for $72 \mathrm{GeV}^{40} \mathrm{Ar}$ as compared with $44 \mathrm{GeV}{ }^{12} \mathrm{C}$ may yield stronger increase in the "enhanced neutron production"-but only an experiment can give the answer. This answer is needed to understand neutron multiplicities in thick targets and to provide proper radiation protection for any new construction of high intensity, high energy heavy-ion accelerators.

Recent calculations using the MCNPX code indicate that the simulated mass yields are model dependent. Conclusions presented here on the $72 \mathrm{GeV} \mathrm{Ar}+\mathrm{Cu}$ results (Figures 7-10) are based on the current results of calculations. A detailed analysis of the MC-calculated mass yields in heavy-ion interactions using all available physics models in the MCNPX code and comparison with the experimental data from the literature is in progress and will be presented in another publication. 


\section{Conclusions}

Neutron ambient dose equivalents have been measured in the irradiation of a $20 \mathrm{~cm}$ thick $\mathrm{Pb}$ target with $1 \mathrm{GeV}$ protons close to the target and at larger distances in the experimental hall. Experiments and calculations based on DCM/CEM code agree within uncertainties. Based on experiments where breeding rates $B\left({ }^{140} \mathrm{La}\right)$ were measured with $1 \mathrm{GeV}$ protons and $44 \mathrm{GeV}{ }^{12} \mathrm{C}$ under similar conditions, one can estimate the neutron ambient dose equivalent during irradiations with $44 \mathrm{GeV}{ }^{12} \mathrm{C}$ onto thick $\mathrm{Pb}$ and $\mathrm{Cu}$ targets close to the target and in the experimental hall. The estimated neutron ambient dose equivalents are on the order of $1000 \mu \mathrm{Sv} / \mathrm{h}$ at about 5 meters distance and behind 1 meter thick concrete shielding for the irradiation parameters given. Such large doses require that humans stay away a considerable distance from the experimental area, maybe more than $50 \mathrm{~m}$. One may observe in these heavy ion irradiations of thick targets some physical phenomena constituting a radiation protection problem connected to the "unresolved problems" as described in $[1,2]$.

Detailed calculations carried out with the MCNPX 2.7a code have shown that radiochemical spallation yield distributions in thick $\mathrm{Cu}$ targets irradiated with $72 \mathrm{GeV}{ }^{40} \mathrm{Ar}$ cannot be reproduced by calculations. Secondary fragments destroy $\mathrm{Cu}$ nuclei stronger than primary $72 \mathrm{GeV}{ }^{40} \mathrm{Ar}$ ions, thus confirming observations reported in $[1,2]$. The neutron ambient dose equivalent in the irradiation of $20 \mathrm{~cm}$ thick $\mathrm{Cu}$ targets with $72 \mathrm{GeV}{ }^{40} \mathrm{Ar}$ is experimentally known to be large, but data have never been published. Such published data would be useful for two reasons:

(i) to design the radiation protection shielding for heavy ion accelerators producing high energy heavy ions with large intensities, and

(ii) to learn more about the physical reason connected with these "unresolved problems."

\section{Acknowledgments}

The authors wish to thank the operators of the Nuclotron accelerator in the LHEP for their continuous efforts to provide first class and stable beams. Considerable part of the work was made in the framework of an International Collaboration (GAMMA-2, Energy plus Transmutation) experimenting at the Nuclotron accelerator in JINR (Dubna, Russia).

\section{References}

[1] R. Brandt, V. A. Ditlov, K. K. Dwivedi et al., " Interactions of relativistic heavy ions in thick heavy element targets and some unresolved problems," Physics of Elementary Particles and Nuclei, vol. 39, no. 2, pp. 507-526, 2008.

[2] R. Brandt, V. A. Ditlov, K. K. Dwivedi et al., "Interactions of relativistic heavy ions in thick heavy element targets and some unresolved problems," Physics of Particles and Nuclei, vol. 39, no. 2, pp. 259-285, 2008.
[3] O. Yordanov, K. Gunzert-Marx, P. Adrich et al., "Neutron yields from $1 \mathrm{GeV} /$ nucleon ${ }^{238} \mathrm{U}$ ion beams on Fe target," $\mathrm{Nu}$ clear Instruments and Methods in Physics Research, Section B, vol. 240, no. 4, pp. 863-870, 2005.

[4] W. Westmeier, R. Brandt, S. R. Hashemi-Nezhad et al., Physics of Elementary Particles and Nuclei. In press.

[5] D. B. Pelowitz, J. S. Hendricks, J. W. Durkee et al., Report LAUR-08-071822, Los Alamos National Laboratory, 2008.

[6] M. Fragopoulou, S. Stoulos, M. Manolopoulou, M. Krivopustov, and M. Zamani, "Dose measurements around spallation neutron sources," Radiation Protection Dosimetry, vol. 132, no. 3, pp. 277-282, 2008.

[7] M. Ochs, I. G. Abdullaev, I. Adam et al., "SSNTD and radiochemical studies on the transmutation of nuclei using relativistic ions," Radiation Measurements, vol. 28, no. 1-6, pp. 255-268, 1997.

[8] J. Adam, J. C. Adloff, A. Balabekyan et al., "Transmutation of ${ }^{239} \mathrm{Pu}$ and other nuclides using spallation neutrons produced by relativistic protons reacting with massive $\mathrm{U}$ - and $\mathrm{Pb}$ targets," Radiochimica Acta, vol. 90, no. 8, pp. 431-442, 2002.

[9] W. Westmeier, R. Brandt, E.-J. Langrock et al., "Transmutation experiments on ${ }^{129} \mathrm{I},{ }^{139} \mathrm{La}$ and ${ }^{237} \mathrm{~Np}$ using the Nuclotron accelerator," Radiochimica Acta, vol. 93, no. 2, pp. 65-73, 2005.

[10] J.-S. Wan, Th. Schmidt, E.-J. Langrock et al., "Transmutation of ${ }^{129} \mathrm{I}$ and ${ }^{237} \mathrm{~Np}$ using spallation neutrons produced by 1.5 , 3.7 and $7.4 \mathrm{GeV}$ protons," Nuclear Instruments and Methods in Physics Research, Section A, vol. 463, no. 3, pp. 634-652, 2001.

[11] R. G. Vasil'kov, Y. M. Chirkin, and N. S. Myzin, "Neutron yield from a massive lead target under the action of relativistic light ions," Atomnaya Energiya, vol. 79, no. 4, pp. 257-264, 1995 (Russian).

[12] V. I. Yurevich, R. M. Yakovlev, R. G. Vassilkov, V. A. Nikolaev, V. G. Lyapin, and I. O. Tsvetkov, "Production and multiplication of neutrons in lead targets induced by protons above $1 \mathrm{GeV}$," Nuclear Instruments and Methods in Physics Research, Section A, vol. 562, no. 2, pp. 747-749, 2006.

[13] M. I. Krivopustov, D. Chultem, J. Adam et al., "First experiments with a large uranium blanket within the installation "energy plus transmutation" exposed to $1.5 \mathrm{GeV}$ protons," Kerntechnik, vol. 68, no. 1-2, pp. 48-55, 2003.

[14] M. I. Krivopustov, A. V. Pavliouk, A. D. Kovalenko et al., "First results studying the transmutation of ${ }^{129} \mathrm{I},{ }^{237} \mathrm{~Np},{ }^{238} \mathrm{Pu}$, and ${ }^{239} \mathrm{Pu}$ in the irradiation of an extended nat $\mathrm{U} / \mathrm{Pb}$-assembly with $2.52 \mathrm{GeV}$ deuterons," Journal of Radioanalytical and Nuclear Chemistry, vol. 279, no. 2, pp. 567-584, 2009.

[15] S. R. Hashemi-Nezhad, I. Zhuk, M. Kievets et al., "Determination of natural uranium fission rate in fast spallation and fission neutron field: an experimental and Monte Carlo study," Nuclear Instruments and Methods in Physics Research, Section A, vol. 391, no. 3, pp. 517-529, 2008.

[16] W. Westmeier, S. R. Hashemi-Nezhad et al. In preparation.

[17] Y. L. Wang, S. L. Guo, C. Q. Tu et al., "Investigation of neutron spectrum emitted from $44 \mathrm{GeV}{ }^{12} \mathrm{C}+\mathrm{Cu}$ interactions with nuclear emulsion," Radiation Measurements, vol. 28, no. 1-6, pp. 269-272, 1997.

[18] R. Brandt, "Measurements of neutron yields and radioactive isotope transmutation in collisions of relativistic ion with heavy nuclei," JINR-Print E1-99-251, Joint Institute for Nuclear Research, Dubna, Russia, 1999, Review-Report for the 85th Session of the JINR Scientific Council.

[19] K. Aleklett, R. Brandt, G. Dersch et al., "Unusual behavior of projectile fragments produced by the interactions of relativistic Ar ions with copper," Physical Review C, vol. 38, no. 4, pp. 1658-1673, 1988. 
[20] J. B. Cumming, P. E. Haustein, T. J. Ruth, and G. J. Virtes, "Spallation of copper by $80-\mathrm{GeV}$ Ar40 Ions," Physical Review C, vol. 17, no. 5, pp. 1632-1641, 1978.

[21] G. Haase, "Kernchemische Studien zum ungewöhnlichen Weitwinkelverhalten von Sekundärteilchen in relativistischen Schwerionenreaktionen," Ph.D. thesis, Fachbereich Physikalische Chemie, Philipps-Universität, Marburg, Germany, 1990. 

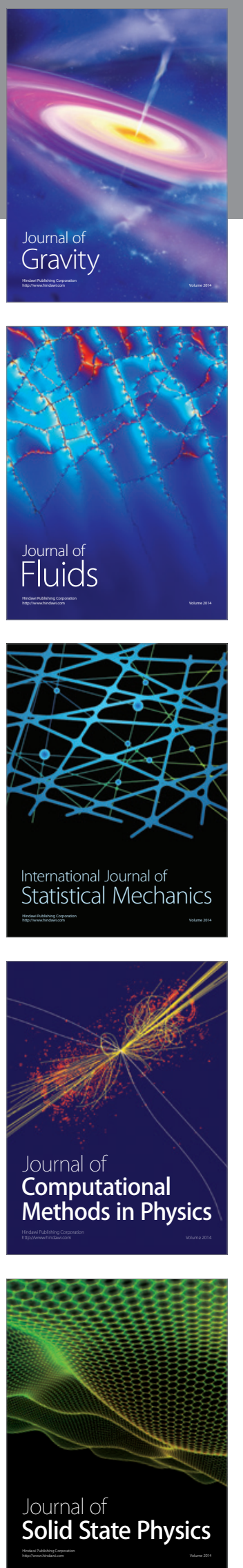

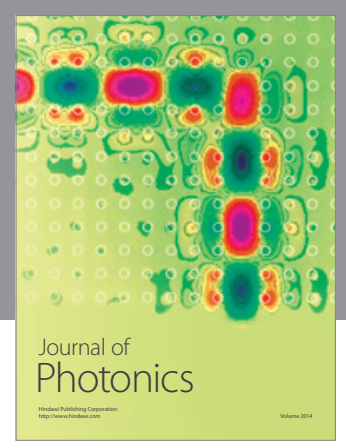

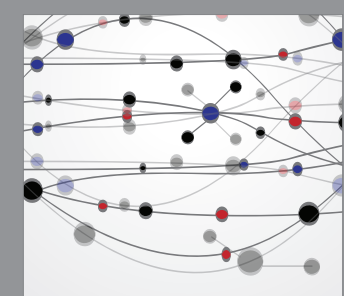

The Scientific World Journal
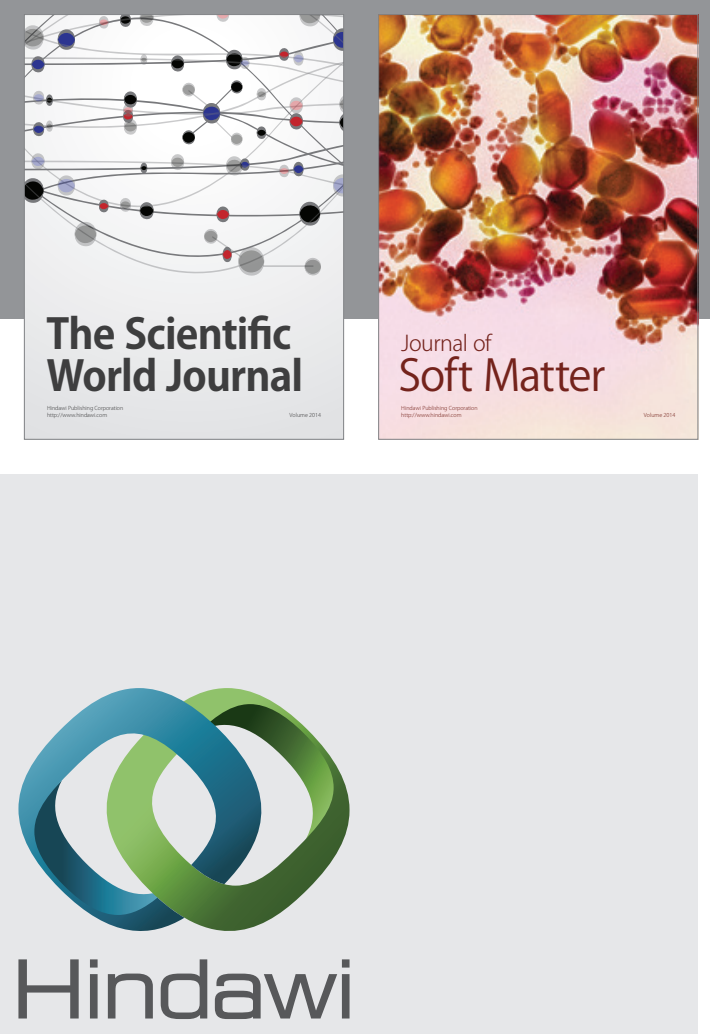

Submit your manuscripts at

http://www.hindawi.com
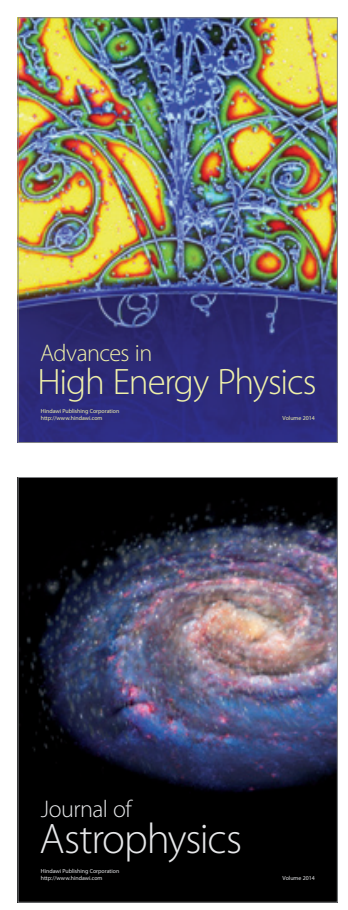
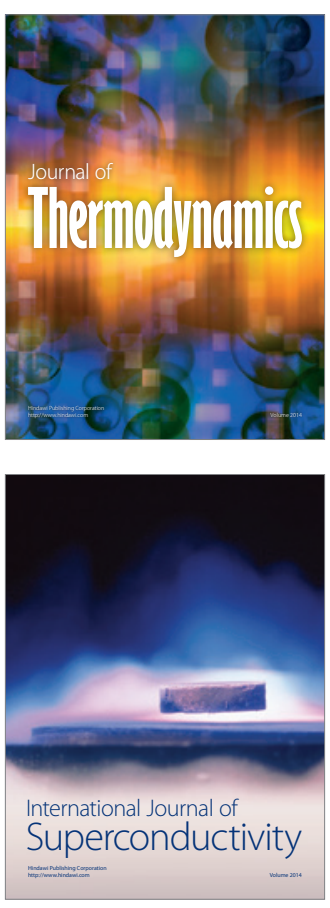
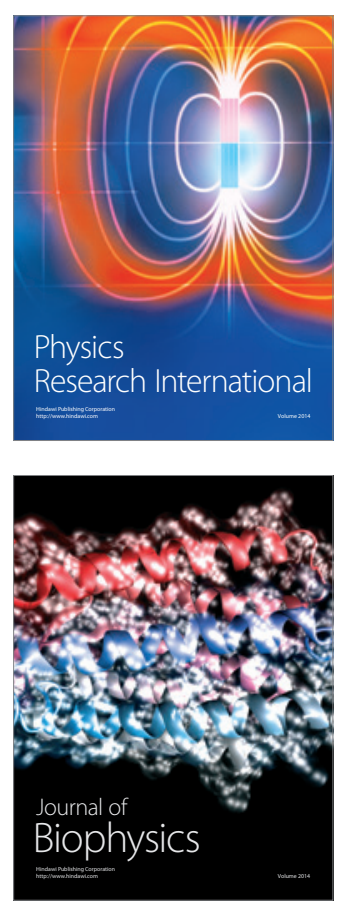
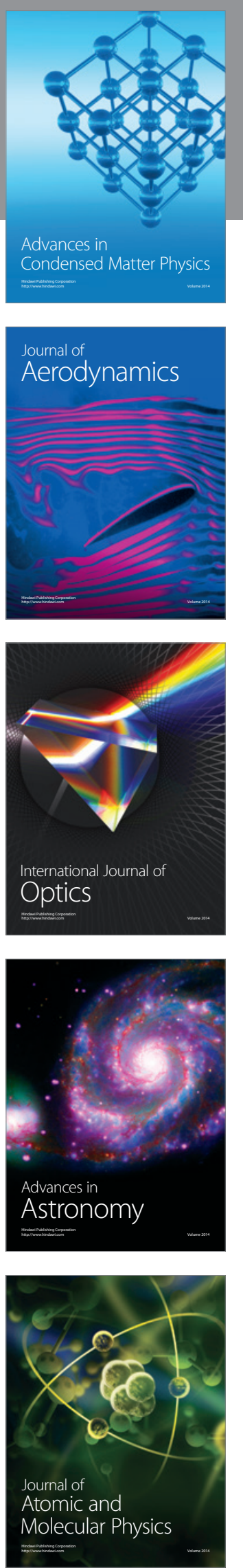